\title{
Safety in numbers: the case for endoscopist-directed propofol sedation
}

Author

Institution
John J. Vargo

Department of Gastroenterology and Hepatology, Digestive Disease Institute, Cleveland, OH, USA submitted:

7. August 2015

accepted after revision:

17. August 2015

\section{Bibliography}

Dol http://dx.doi.org/

$10.1055 / \mathrm{s}-0034-1393086$

Endoscopy International Open 2015; 03: E398-E399

(c) Georg Thieme Verlag KG Stuttgart · New York

E-ISSN 2196-9736

\section{Corresponding author}

John J. Vargo, MD

Department of

Gastroenterology and

Hepatology

Digestive Disease Institute

Desk A-30

Cleveland Clinic

9500 Euclid Avenue

Cleveland

$\mathrm{OH}$

USA

Fax: +1-216-444-6284

VARGO]@ccf.org
In this volume of Endoscopy International Open, Ooi and Thomson [1] present a series of over 33,000 endoscopic procedures over a 9-year period that were performed with endoscopist directed, nurse-administered propofol sedation at a tertiary referral center. To be more specific, most patients received a combination of fentanyl, midazolam, and propofol, more commonly known as balanced propofol sedation. The primary outcome was the response of an institutional emergency medical response team as a surrogate for a severe cardiopulmonary unplanned event. The authors found that the incidence of emergency response team events was quite uncommon (23/33,539 procedures, $0.07 \%$ ). Of these 23 instances, 18 were in patients receiving an upper endoscopy. Seventeen patients exhibited advanced American Society of Anesthesiologists (ASA) physical status classification scores (ASA III: 15; ASA IV: 2), and 12 were being evaluated for upper gastrointestinal bleeding. All seven instances of urgent intubation occurred in the esophagogastroduodenoscopy (EGD) group and two of these eventually died. In both deaths, the indication for the upper endoscopy was for upper gastrointestinal bleeding with advanced ASA physical status classification. Interestingly, in both cases, there did not appear to be evidence of aspiration.

Given the rarity of the events, it is impossible to perform any meaningful statistical analysis, yet the descriptive pattern of patients at risk for significant cardiopulmonary unplanned events is quite similar to the study of Rex et al. [2]: the incidence of airway intervention was higher in subjects receiving an EGD and mortality was seen in those with advanced malignancy or other serious medication conditions. One could make the argu- ment that, in the majority of the cases with upper gastrointestinal bleeding who required the emergency response team, the reason for the urgent intervention was not as a result of the propofol sedation per se, but due to the tempo of bleeding which required airway intervention. The mortality rate in the Rex study was much lower however $(4 / 646,080,0.0006 \%)$. The reasons for this are unknown, but patient selection, heterogeneity in the administration algorithms of propofol, and the use of additional agents may have played a role.

A particular strength of the study is the fact that the nurse sedationist training and competency requirement were standardized and quite comprehensive. This involved a yearly practical and written assessment, demonstration of airway management competency, and a minimum threshold volume of at least 250 annual procedures in order to remain qualified.

There are several shortfalls with this study. Patient selection did not include a formal ASA physical status classification, urgency of the procedure, Mallampati score, or the exclusion of patients with gastroparesis. The actual targeted depth of sedation appears to have been variable (moderate or deep sedation) as response to repeated tactile or noxious stimuli was required. An emergency response team call was also made for decreased levels of consciousness which was not further defined. A standardized dosing algorithm for the opioid and benzodiazepine did not appear to be utilized. There is also no data as to whether reversal agents or other airway measures such as nasopharyngeal tube placement were employed which may have averted an emergency response team call. Also, there was not an- 
other instance of endotracheal intubation after 2008. This may reflect a systematic change in training, management, and/or patient selection.

In conclusion, this study emphasizes that with proper training and prudent patient selection, endoscopist-directed propofol sedation is safe and effective. Hopefully, we can look forward to the day when this evidence-based practice will be universally adopted.

\section{Competing interests: None}

\section{References}

1 Ooi M, Thomson A. Morbidity and mortality of endoscopist-directed nurse-administration or propofol sedation (EDNAPS) in a tertiary referral center. Endosc Int Open 2015; 3: 00-00 घpage numbers to be completed once known

2 Rex DK, Deenadayalu VP, Eid E et al. Endoscopist-directed administration of propofol: a worldwide safety experience. Gastroenterology 2009; 137: 1229-1237 